\title{
Kalorisi azaltılmış mor reyhan soğuk çayı üretimi
}

\author{
Production of reduced calorie purple basil iced tea
}

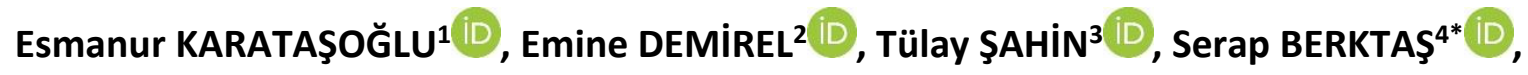 \\ Mustafa ÇAM ${ }^{5}$ iD
}

1,2,3,4,5Erciyes Üniversitesi, Mühendislik Fakültesi, Gıda Mühendisliği Bölümü, Kayseri, Türkiye ${ }^{1}$ https://orcid.org/0000-0002-2662-4044; ${ }^{2}$ https://orcid.org/0000-0003-1829-5241; ${ }^{3}$ https://orcid.org/0000-0002-3050-3819; ${ }^{4}$ https://orcid.org/0000-00025195-0685;5https://orcid.org/0000-0003-1258-0834

To cite this article:

Karataşoğlu, E., Demirel, E., Şahin, T., Berktaş, S. \& Çam, M. (2021). Kalorisi azaltılmış mor reyhan soğuk çayı üretimi. Harran Tarım ve Gıda Bilimleri Dergisi, 25(2): 163-171

DOI:10.29050/harranziraat.798081

\section{*Address for Correspondence: Serap BERKTAŞ e-mail: \\ berktaserap@gmail.com}

Received Date:

21.09.2020

Accepted Date:

06.04.2021

\section{Öz}

Bu çalışmada, mor reyhan ekstraktı (MRE) ve şeker alkolleri ile geliştirilen düşük kalorili soğuk çayların duyusal kabul edilebilirlikleri araştırılmıştır. MRE, sitrik asit ve sakaroz ile 9 farklı formülasyonda hazırlanan soğuk çayların ön duyusal değerlendirmeleri sonucu referans formülasyon (T3) (MRE: sitrik asit: sakaroz, 1.5: 0.15: 8, \%, (v: w: w) / v)) belirlenmiştir. Sorbitol (T4) ve ksilitol (T5) kullanılarak hazırlanan düşük kalorili soğuk çaylar referans örnek (T3) ile duyusal açıdan karşılaştırılmıştır. Duyusal analiz sonuçlarına göre şeker alkolleri ile üretilen soğuk çayların sakaroz kullanılarak üretilene göre reyhanın aroma ve tadını daha çok öne çıkardığı ve daha çok beğeni aldıkları panelistlerce belirlenmiştir. Mor reyhan soğuk çayı, hem reyhanın sahip olduğu fenolik bileşikleri içermesi hem de şeker alkolleri kullanımı sonucu kalorisinin azaltılması ile diğer soğuk ya da sıcak olarak tüketilen içeceklere iyi bir alternatif olabilecek nitelikte bir içecek olabileceği sonucuna ulaşılmıştır.

Anahtar Kelimeler: Düşük kalori, Soğuk çay, Mor reyhan, Şeker alkolü

\section{ABSTRACT}

In this study, the sensory acceptability of low-calorie iced teas developed with purple basil extract (MRE) and sugar alcohols was investigated. The reference formulation (T3) (MRE: citric acid: sucrose, 1.5: 0.15: 8,\%, ( $\mathrm{v}: \mathrm{w}: \mathrm{w}) / \mathrm{v}$ )) was determined as a result of the preliminary sensory evaluations of iced teas prepared in 9 different formulations with MRE, citric acid and sucrose. Low calorie iced teas prepared using sorbitol (T4) and xylitol (T5) were compared with the reference sample (T3) in sensory aspects. According to the results of the sensory analysis, it was determined by the panelists that iced teas produced with sugar alcohols highlight the aroma and taste of basil more than those produced using sucrose, and they received more appreciation. It has been concluded that purple basil iced tea can be a good alternative to other iced or hot beverages due to the fact that it contains phenolic compounds of basil and its calorie reduction due to the use of sugar alcohols.

Key Words: Low calorie, Iced tea, Purple basil, Sugar alcohol

\section{Giriş}

Insanların giderek artan daha sağ|ıklı ve kaliteli yaşam isteğine bağlı olarak şekersiz ürünlere olan talepleri de gün geçtikçe artmaktadır (Diffy ve Anderson, 1998). Kalorisi yüksek diyetler hakkında artan farkındalık, tatlı algısından ödün vermeden düşük enerjili tatlandırıcıların araştırılmasına yol açmıştır (Butt ve ak., 2002). Bununla birlikte, şekerle (monosakkaritler ve disakkaritler) tatlandırımış içeceklerin tüketimi hem yetişkinlerde hem de çocuklarda kilo alımı ve 
obezitedeki artışa giderek daha çok bağlanmaktadır. Antidiyabetik ve obezite önleyici özelliklere sahip fonksiyonel bileşenlerle birlikte formülize edilmiş düşük şeker içeriğine sahip içecekler bu nedenle ikili bir fayda sağlayacaktır (Złotek ve ark., 2017; de Beer ve ark., 2018).

Şeker alkolleri (polioller) doğal olarak gıdanın yapısında bulunan veya endüstriyel olarak şekerlerden üretilebilen beyaz, suda çözünür organik bileşiklerdir. Gıdalarda yaygın olarak bulunan şeker alkolleri sorbitol, mannitol, ksilitol, izomalt ve hidrojene nişasta hidrolizatlarıdır (Grembecka, 2015). Şeker alkolleri, sakaroz ile kıyaslandığında metabolizması vücutta tam olarak gerçekleşmemektedir. Dolayısıyla emilimi çok yavaş olduğundan daha az kalori sağlamakta ve kan şekeri düzeyini daha az etkileyebilmektedir (Butt ve ark., 2002; Kim ve ark., 2016; Godswill, 2017). Bundan dolayı, polioller diyabetik ve diyet ürünlerinde kullanılmaktadır (Warshaw ve Powers, 1999). Ayrıca, bu tatlandırıcılar şeker ikameleri veya hacim artırıcılar olarak da adlandırılmaktadır (Kroger ve ark., 2006). Kalori azaltma ve karyojenik olmama gibi temel şekerlere göre bazı avantajları bulunmasının yanı sıra aşırı tüketimi durumunda laktasif etki gibi dezavantajları da bulunmaktadır (Cammenga ve ark., 1996; Grembecka, 2015). Ayrıca, ticari gıda maddelerinde şeker alkolleri, genellikle düşük tatııı̆ı engellemek adına genellikle yüksek yoğunluklu yapay tatlandırıcılar ile birlikte sakaroz yerine kullanılmaktadır. "Şekersiz" veya "şeker eklenmemiş" olarak adlandırılan birçok "diyetetik" gıda aslında şeker alkolü içermektedir. Şeker alkolleri sakarozdan daha tatlı olmamakla birlikte bazıları, yüksek oranda konsantre edildiğinde ağızda belirgin bir soğutma hissi verebilirler (Cammenga ve ark., 1996). Bu hissi veren şeker alkollerinden biri olan ksilitol, görsel özellikleri ve sağladığı tatlılık düzeyi sakaroz ile benzerlik göstermekte olup en çok kullanılan şeker alkollerinden biridir. Diş dostu olarak bilinen ksilitol sakaroz ile aynı tatlılığa sahip iken yaklaşık \%33 daha az kalori içermektedir. Sorbitol ise genellikle diyet ürünlerde sıklıkla kullanılmakla birlikte sakarozun \%60' । kadar tatılığa sahiptir ve yaklaşık \%30 daha az kalori içermektedir (Grembecka, 2015; Godswill, 2017).

Reyhan (Ocimum basilicum L.) dünya çapında geleneksel olarak yetiştirilen ve Lamiaceae familyasına ait, tıbbi ve aromatik bir bitkidir. Fesleğen adı ile de bilinen reyhan, Hindistan, Afrika ve Güney Asya kökenli olup en popüler ve kolaylıkla bulunabilen mutfak ve süs bitkilerinden biridir. (Flanigan ve Niemeyer, 2014; Szymanowska ve ark., 2015). Tüm cinsine ortak bir isim verilen bu tür, farklı morfolojik özellikleri, kimyasal bileşimi ve tarımsal endüstride kullanımları olan çok sayıda çeşidi içermektedir. Reyhanın en çok bilinen türleri ise yeşil yapraklı ve beyaz çiçekli olan yeşil reyhan ve antosiyaninlerin yaprak ve çiçeklerinde birikmesi sonucu mor renkte olan mor reyhandır (Prinsi ve ark., 2020). Pek çok reyhan türünde rosmarinik asit, kafeik asit ve kaftarik asit başta olmak üzere pek çok fenolik asit üyesi yüksek miktarda bulunmaktadır. Ayrıca, mor reyhan çeşidine bağlı olarak önemli miktarda suda çözünen fenolik bileşik antosiyaninleri içermektedir (Pedro ve ark., 2016). Yeşil reyhan her ne kadar yüksek antioksidan kapasiteye sahipse de mor reyhandaki antosiyaninlerin varlığı pek çok biyolojik aktiviteyi güçlendirmektedir. Bu etkiler çeşitler arasındaki kimyasal bileşim farklılığı ve özellikle farklı biyolojik aktivitelere sahip bireysel bileşiklerin varlığından kaynaklanmaktadır (Flanigan ve Niemeyer, 2014). Reyhan ile ilgili yapılan çalışmalar incelendiğinde de pek çok çalışmanın bitkinin antioksidan, antimikrobiyel, antiinflamatuvar, hipoglisemik, hepatoprotektif ve kardiyoprotektif gibi biyoaktif özellikleri ile ilgili olduğu göze çarpmaktadır (Phippen ve Simon, 1998; Flanigan ve Niemeyer, 2014; Szymanowska ve ark., 2015; Złotek ve ark., 2016; Koroch ve ark., 2017).

Çay (Camellia sinensis) ülkemizde yoğun şekilde tüketilen önemli biyoaktif bileşik kaynaklarından biridir. Geleneksel çay hazırlama işleminin zaman alıcı olması nedeniyle alternatif ürünler ortaya çıkmıştır. Bu ürünlerden poşet çay ve soğuk çay ön plandadır. Siyah çay ile üretilen soğuk çaylar yıllardır satışa sunulmaktadır ancak 
diğer bitkisel materyallerin soğuk çay üretiminde kullanımı çok nadirdir (Alaşalvar ve Çam, 2020). Ayrıca soğuk çaylar içerisindeki sakaroz miktarı nedeniyle bilinçli tüketiciler tarafından genellikle şüphe ile yaklaşılmakta veya uzak durulmaktadır. Tüketime hazır içeceklerin şeker içeriği göz önüne alındığında şeker miktarı ve kan şekeri seviyesi arasındaki doğrusal ilişki nedeniyle bu içecekler hakkında artan endişeler bulunmaktadır. Pek çok çalışmada ve farklı gıda ürünlerinde bu endişeleri bertaraf etmek için doğal ya da yapay tatlandırıcılar kullanılmaktadır (Kroger ve ark., 2006; DellaValle ve ark., 2018; SamaniegoVaesken ve ark., 2019). Diğer yandan, özellikle yapay tatlandırıcı içeren ürünlerin tüketimlerinden sonra acı tat hissi ve ağızda meydana gelen kalıntı tat tüketiciler tarafından arzu edilmeyen bir durum olarak kabul edilmektedir (Sylvetsky ve Rother, 2016).

Literatür çalışmaları incelendiğinde, mor reyhanın kullanıldığı düşük kalorili soğuk çay üretiminin gerçekleştirildiği bir çalışmaya rastlanılmamıştır. Bununla birlikte, bitkilerin soğuk çay formülasyonunda kullanıldığı sınırlı sayıda çalışma bulunmaktadır. Bu çalışmada, mor reyhan ekstaktının bitkisel soğuk çay üretiminde girdi olarak kullanımı ve ayrıca sakaroz yerine ksilitol ve sorbitol kullanımı ile düşük kalorili bitkisel soğuk çayların üretimi amaçlanmıştır.

\section{Materyal ve Metot}

\section{Materyal}

Mor reyhan kurutulmuş formda yerel bir aktardan (Aktariyem, Kayseri), sorbitol ve ksilitol ise toz formda (Tito, Türkiye) temin edilmiştir Deneysel çalışmalarda kullanılan tüm kimyasal ve çözücüler Sigma-Aldrich (St. Louis, MO, USA) ve Merck (Darmstadt, Germany) firmalarından alınmıştır.

\section{Mor reyhan ekstraktlarının hazırlanması}

Soğuk çay formülasyonlarına eklenecek mor reyhan ekstraktı (MRE) hazırlamak amacıyla ilk olarak kuru formdaki reyhan yaprakları saplarından ayrılarak laboratuvar tipi bir ögütücü yardımıyla (Waring Blender, Staufen, Almanya) homojen hale getirilmiştir. Ekstraksiyon sıcaklığının belirlenmesi amacıyla $50{ }^{\circ} \mathrm{C}, 70^{\circ} \mathrm{C}$ ve $100{ }^{\circ} \mathrm{C}^{\prime}$ de ön denemeler yapılarak ekstraktlar alınmıştır. Bunlar arasında $70{ }^{\circ} \mathrm{C}^{\prime}$ de elde edilen ekstraktın diğer örneklere kıyasla en yüksek absorbansı verdiği spektrofotometrede (Shimadzu, UV 1800, Japonya) UV-vis absorbans spektrumu taraması ile belirlenmiştir. Bu işlemi takiben 50 gram homojen hale getirilmiş reyhan tartılarak $300 \mathrm{~mL}$ saf su eklenmiş ve $70{ }^{\circ} \mathrm{C}, 100$ rpm de çalkalamalı su banyosunda (Nüve, NFR800R, Ankara, Türkiye) 30 dakika ekstraksiyon işlemi gerçekleştirilmiştir (Gürkan ve ark., 2018). Ardından elde edilen ekstrakt kaba filtre kâğıdı ile filtre edilerek analiz ve üretimlere kadar $-18{ }^{\circ} \mathrm{C}$ de muhafaza edilmiştir.

\section{Soğuk çay formülasyonunun geliştirilmesi}

Mor reyhan soğuk çaylarının üretimine geçilmeden önce sırasıyla formülasyonda kullanılacak MRE, sitrik asit ve sakaroz oranları panelistler tarafından gerçekleştirilen duyusal değerlendirmeler ile belirlenmiştir (Şekil 1). Bu amaçla ilk olarak sitrik asit (0.15 g) ve sakaroz miktarı (7 g) sabit tutulmuş, MRE miktarı ise $1 \mathrm{~mL}$ (E1), $1.5 \mathrm{~mL}$ (E2) ve $2 \mathrm{~mL}$ (E3) olacak şekilde 3 farklı soğuk çay hazırlanarak duyusal değerlendirmeye alınmıştır. Duyusal değerlendirmeler sonucunda $1.5 \mathrm{~mL}$ MRE içeren soğuk çay örneği daha çok tercih edilmiştir. Daha sonra formülasyonda kullanılacak olan sitrik asit miktarı belirlenmiştir. Bunun için MRE $(1.5 \mathrm{~mL})$ ve sakaroz miktarı (7 g) sabit tutularak $0.1 \mathrm{~g}$ (C1), $0.15 \mathrm{~g}$ (C2) ve $2 \mathrm{~g}$ (C3) sitrik asit içeren soğuk çayların duyusal değerlendirmeleri yapılmıştır. Değerlendirmelere göre $0.15 \mathrm{~g}$ sitrik asit içeren soğuk çay seçilmiştir. Son olarak ise $6 \mathrm{~g}$ (T1), $7 \mathrm{~g}$ (T2) ve $8 \mathrm{~g}$ (T3) sakaroz içeren soğuk çaylardan $8 \mathrm{~g}$ sakaroz içeren soğuk çay örneği panelistlerce tercih edilerek referans soğuk çay formülasyonu (T3) oluşturulmuştur. 


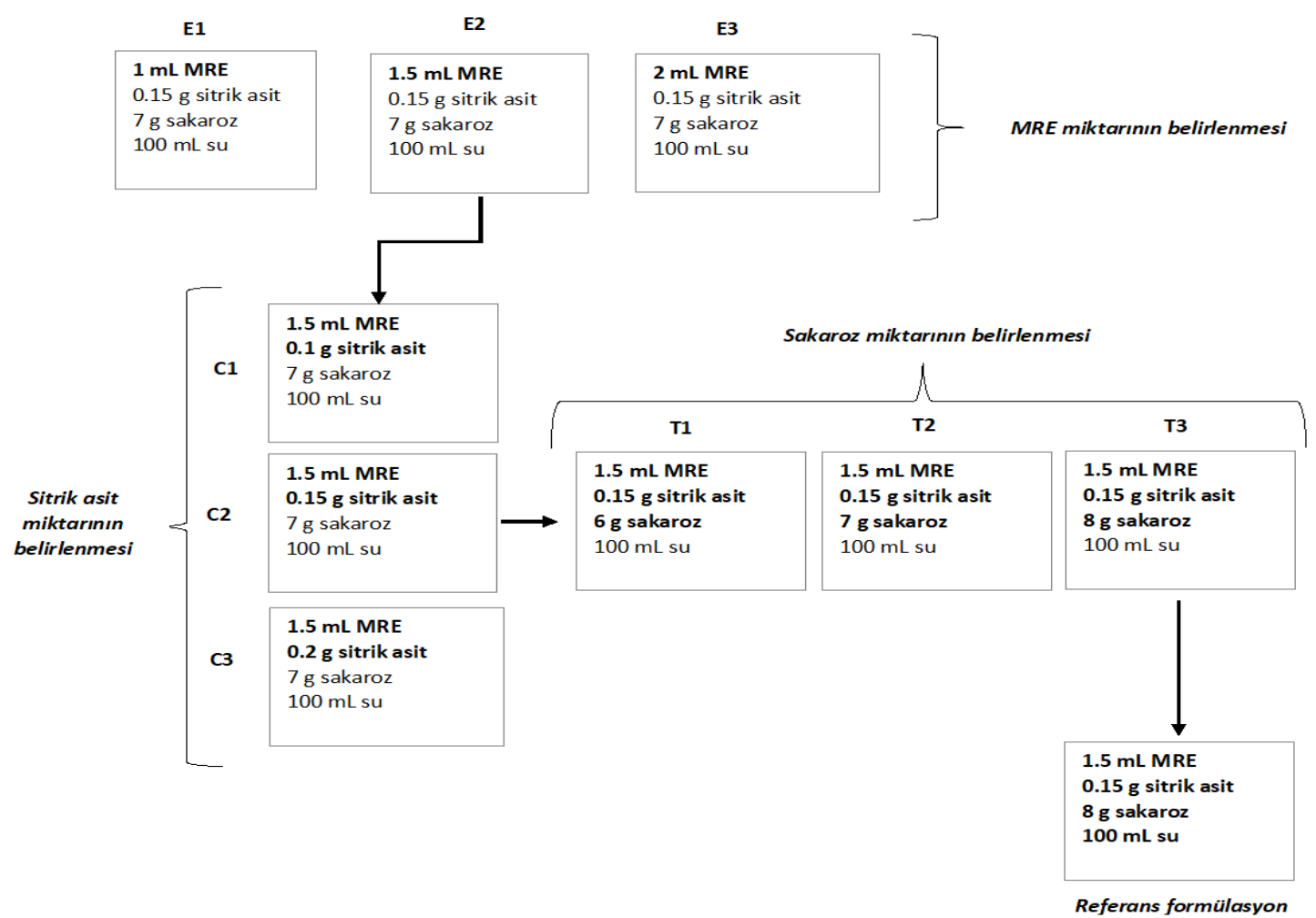

Şekil 1. Soğuk çay formülasyonunun geliştirilmesi Figure 1. Development of the iced tea formulation

Sakaroz ile belirlenen referans soğuk çay formülasyonu (T3) hazırlanarak $250 \mathrm{~mL}$ hacimli steril cam şişelere doldurulmuş ve $80^{\circ} \mathrm{C}$ de $10 \mathrm{dk}$ pastörizasyon işlemi gerçekleştirilmiştir. Şeker alkolü (ksilitol ve sorbitol) içeren soğuk çaylar (T4 ve T5) ise hazırlanırken tatlandırıcı miktarları kalorinin azaltılması amacıyla sakaroz ile aynı miktarda kullanılmıştır (Çizelge 1). Üretimleri yapılan soğuk çaylar analizlere kadar $4{ }^{\circ} \mathrm{C}$ de depolanmıştır.

Çizelge 1. Soğuk çayların kompozisyonu

Table 1. Composition of the iced teas

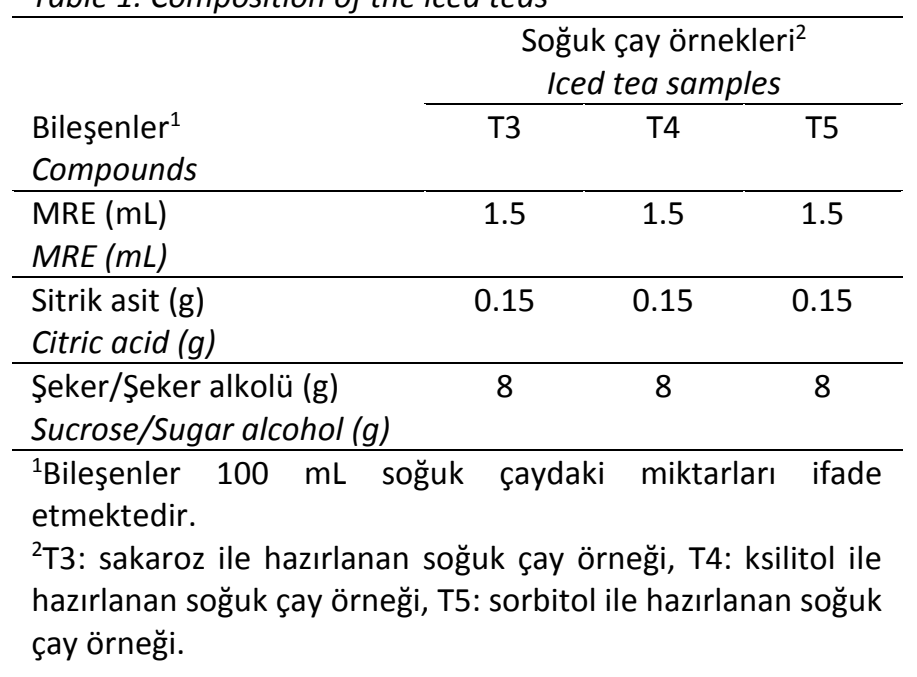

\section{Fizikokimyasal analizler}

Soğuk çay örneklerinin toplam kuru madde miktarlarının belirlenmesi amacıyla $10 \mathrm{~mL}$ örnek alınarak $70{ }^{\circ} \mathrm{C}$ de 24 saat etüvde (GEMO, DT104, Türkiye) neminin uzaklaşması sağlanmıştır. Sonuçlar \% kuru madde olarak ifade edilmiştir. Suda çözünür kuru madde (\%briks) değerlerinin belirlenmesinde Abbe refraktometresi (SOIF, 2WAJ, Çin) kullanılmıştır. Örneklerin pH değerleri bir pH metre (Hanna, İtalya) ile direkt olarak ölçülmüştür. Titre edilebilir asitlik değerleri ise 10 $\mathrm{mL}$ örneğin $0.1 \mathrm{~N} \mathrm{NaOH}$ ile $\mathrm{pH}^{\prime}$ nın 8.1 olduğu noktada titrasyon işlemi durdurularak sarfiyatın not edilmesi ile belirlenmiş ve sonuçlar sitrik asit cinsinden ifade edilmiştir (Cemeroğlu, 2013). Soğuk çayların renk yoğunluğu ekstraktın maksimum absorbans yaptığı dalga boyu olan 408 $\mathrm{nm}^{\prime}$ de spektrofotometrede tespit edilmiştir ( $\mathrm{Wu}$ ve ark., 2014).

\section{Duyusal analiz}

Duyusal değerlendirmeler formülasyon belirlenmesinin her aşamasında ve kalorisi düşük ürünlerin değerlendirilmesinde gerçekleştirilmiştir. Soğuk çaylar $4{ }^{\circ} \mathrm{C}^{\prime}$ de 
buzdolabında soğutularak rastgele 3 rakamlı kodlamalarla etiketlenmiş şeffaf bardaklarda ( 40 $\mathrm{mL}$ ) panelistlere sunulmuştur. Değerlendirmeler, Gıda Mühendisliği Bölümü öğrenci ve öğretim elemanları arasından seçilen 22-50 yaşları arasındaki 30 panelist tarafından gerçekleştirilmiştir. Soğuk çayların renk, tat, koku, asitlik, aroma, ağız hissi ve genel beğeni açısından duyusal değerlendirmeleri 5 puanlı hedonik skala testine (1: çok kötü, 5: mükemmel) göre gerçekleştirilmiştir (Alaşalvar ve Çam, 2020).

\section{Istatistiksel analiz}

Analizlerin sonuçları 2 tekrarlı verilerin ortalama \pm standart sapma değerleri olarak verilmiştir. Örneklerin karşılaştırmaları anlamlılık değeri $(P<0.05)$ göz önüne alınarak Tukey çoklu karşılaştırma testi ile değerlendirilmiştir (SPSS Inc., Chicago, USA).

\section{Araştırma Bulguları ve Tartışma}

\section{Soğuk çayların fizikokimyasal özellikleri}

Düşük kalori içeriği ile tatılığı tüketiciler tarafından kabul gören soğuk çay içeceklerinin hazırlanması için sakaroz ikamesi olarak sorbitol ve ksilitol kullanılmıştır. MRE ile üretilen kalorisi düşük soğuk çayların kuru madde, briks, $\mathrm{pH}$ ve titre edilebilir asitlik değerleri Çizelge 2' de verilmiştir. Bununla birlikte üretilen soğuk çayların kalori değerleri de hesaplanmıştır (Godswill, 2017). Titre edilebilir asitlik açısından örnekler arasında anlamlı bir farklılı ( $>>0.05)$ bulunmamaktadır. Kuru madde, briks ve $\mathrm{pH}$ değerleri ise seçilen tatlandırıcı çeşidinin değişmesine bağlı olarak örnekler birbirinden anlamlı şekilde farklılaşmaktadır. Formülasyondaki toplam bileşim düşünüldüğü zaman 3 soğuk çay da aynı içeriğe sahip iken sadece tatlandırıcı çeşidi farklılaşmaktadır. Sakarozun sıcaklık ve sitrik asit varlığında hidrolize uğraması sonucu invert şekerin oluşması olasılığı sakaroz içeren örnekteki kuru madde ve briks değerlerinin yüksek çıkması ile bağlantılı olabileceği düşünülmektedir (Grembecka, 2015).
Tatlandırıcı olarak şeker alkolünün kullanımı soğuk çayların $\mathrm{pH}$ değerlerini anlamlı şekilde $(P<0.05)$ düşürmüştür. Ürünlere katılan $0.15 \mathrm{~g}$ sitrik asit her bir örnek için pH değerini 3'ün altına indirmiştir ki bu değer gerek pastörizasyon süresinin kısalmasına yardımcı olmakta gerekse ürünleri görece daha güvenli kılmaktadır. Enginarlı-limonlu soğuk yeşil çayların özelliklerinin belirlendiği bir çalışmada soğuk çayların briks değerleri 5.60-7.55 olarak, titre edilebilir asitlik değerleri ise 1.16-1.24 g sitrik asit/100 mL olarak tespit edilmiştir (Özünlü ve Ergezer, 2019). Nane ekstraktlarının soğuk çay üretiminde kullanıldığı başka bir çalışmada ise örneklerin $\mathrm{pH}$ değerleri 3.45-3.99, briks değerleri ise 7.2-8.1 g/100 mL olarak belirlenmiştir (Alaşalvar ve Çam, 2020). Aonla meyvesi-zencefil suyu ve yapay tatlandırıcılar kullanılarak düşük kalorili bitkisel çayın üretildiği çalışmada içeceklerin asitlik değerleri \%0.3-0.38, pH değerleri ise 3.0-3.5 olarak belirlenmiştir (Gaikwad ve ark., 2012). Toğrul ve Hayoğlu (2020) çeşitli meyvelerle zenginleştirmiş oldukları elma suyu içeceklerinde $\mathrm{pH}$ değerlerini $5^{\prime}$ in altında tespit etmişlerdir. Bu çalışmalardaki değerler incelendiğinde çalışmamızdaki soğuk çayların briks değerleri ile uyumlu görünmektedir. Soğuk çayların bileşiminde bulunan şeker ikamelerine bağlı olarak ise fizikokimyasal özelliklerin değiştiği ve kabul edilebilir düzeyde olduğu görülmektedir.

Gıda ürünlerinde özellikle içeceklerde tüketici kabulünü etkileyen önemli unsurlardan birisi olan renk farklı metotlarla belirlenebilmektedir (Bello ve ark., 2015; Cheng ve ark., 2018). Antosiyanince zengin mor reyhanlı soğuk çayların yüksek absorbans verdiği dalga boyunda spektrofotometrede ölçüm yapılmıştır. Soğuk çayların $408 \mathrm{~nm}$ deki renk yoğunluğu değerlerine bakıldığında (Şekil 2) ksilitol ile tatlandırılan örneğin renk yoğunluğu değerinin en yüksek olduğu görülmektedir. Mor reyhanda bol miktarda bulunan antosiyaninlerin bitkiye rengini verdiği ve bunu da en iyi ksilitollü örneğin yansıttığı görülmektedir. 
Çizelge 2. Soğuk çayların fizikokimyasal özellikleri

Table 2. Physicochemical properties of iced teas

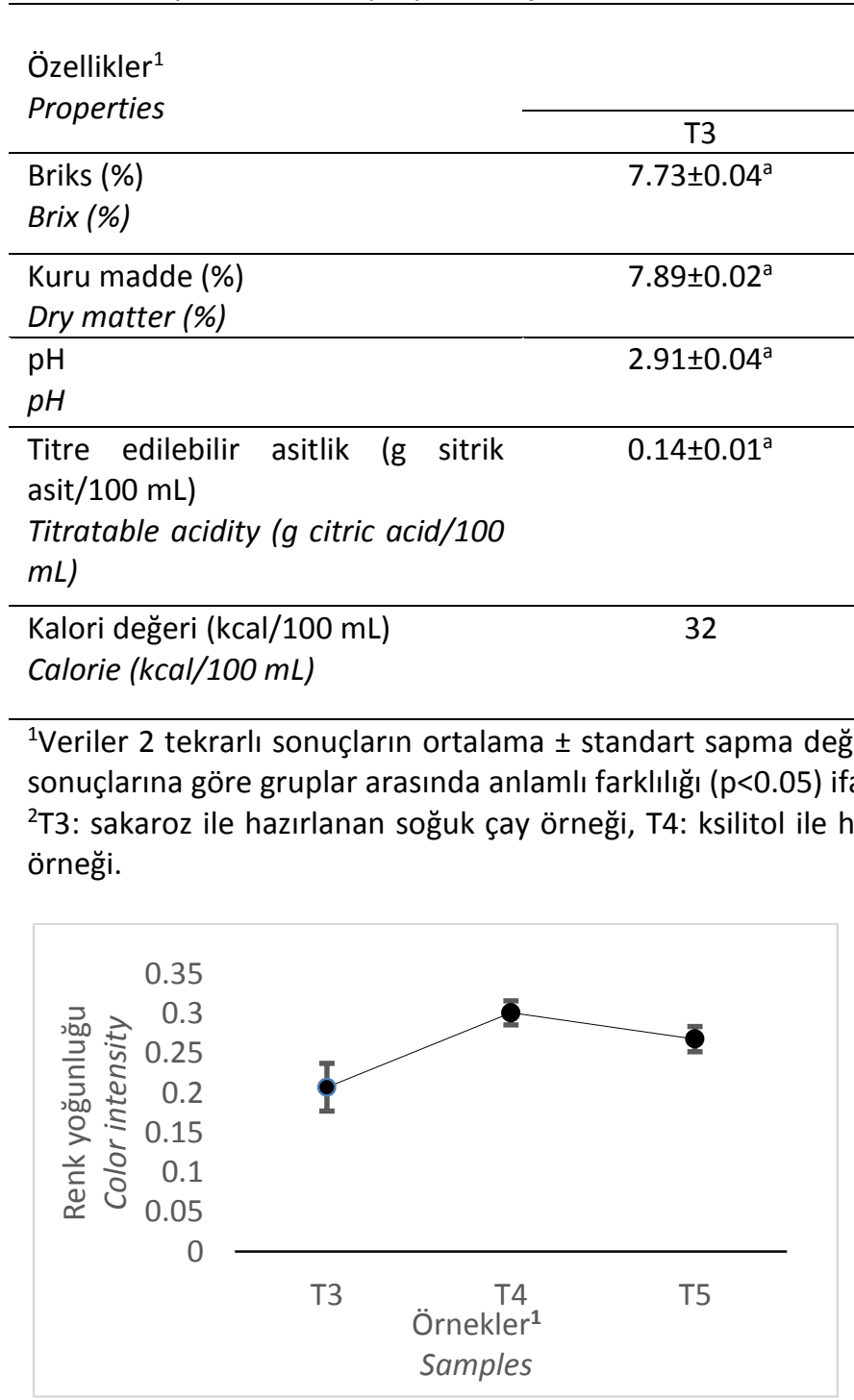

Şekil 2. Soğuk çayların renk yoğunluğu değerleri

Figure 2. Color intensity values of iced tea

${ }^{1} \mathrm{~T} 3$ : sakaroz ile hazırlanan soğuk çay örneği, T4: ksilitol ile hazırlanan soğuk çay örneği, T5: sorbitol ile hazırlanan soğuk çay örneği.

\section{Soğuk çayların duyusal özellikleri}

\section{Formülasyonun belirlenmesi}

Soğuk çay formülasyonu, yapılan duyusal denemeler ile sırasıyla MRE (1.0-2.0 mL/100 mL), sitrik asit (0.1-0.2 g/100 mL) ve şeker (6.0-8.0 $\mathrm{g} / 100 \mathrm{~mL}$ ) miktarları değiştirilerek belirlenmiştir (Çizelge 3, Çizelge 4 ve Çizelge 5). Bu amaçla ilk olarak farklı MRE miktarını içeren soğuk çaylar panelistlere sunulmuş ve duyusal değerlendirmeleri yapılmıştır (Çizelge 3). Tatlılık, asitlik, koku ve genel beğeni açısından örnekler arasında anlamlı bir fark ( $P>0.05)$ bulunmamıştır. Ancak, \%1.5 (v/v) MRE içeren E2 kodlu soğuk çay örneği, duyusal parametrelere verilen beğeni puanları göz önünde bulundurulduğunda öne

çıkmaktadır. Biyoaktif bileşiklerce zengin bitkisel ekstraktların formülasyonda yüksek miktarda bulunması ürünlerin fenolik madde içeriğinde artışa neden olmasının yanı sıra ürünlerin duyusal kabul edilebilirliğinde azalmaya neden olabilmektedir (Alaşalvar ve Çam, 2020). Duyusal sonuçlardan da anlaşılacağı üzere \%1.5 (v/v) MRE oranından sonra genel beğenide azalma tespit edilmiştir.

Çizelge 3. MRE miktarının belirlenmesi

Table 3. Determining the amount of MRE

\begin{tabular}{|c|c|c|c|}
\hline \multirow[b]{2}{*}{$\begin{array}{l}\text { Duyusal özellikler } \\
\text { Sensory properties }\end{array}$} & \multicolumn{3}{|c|}{$\begin{array}{l}\operatorname{MRE}(\%, \mathrm{v} / \mathrm{v}) \\
\operatorname{MRE}(\%, \mathrm{v} / \mathrm{v})\end{array}$} \\
\hline & 1 & 1.5 & 2 \\
\hline $\begin{array}{l}\text { Renk } \\
\text { Color }\end{array}$ & $3.16 \pm 0.98^{\mathrm{a}}$ & $4.33 \pm 0.81^{b}$ & $4.83 \pm 0.40^{\mathrm{b}}$ \\
\hline $\begin{array}{l}\text { Tatlılık } \\
\text { Sweetness }\end{array}$ & $3.33 \pm 1.21^{\mathrm{a}}$ & $3.67 \pm 0.51^{\mathrm{a}}$ & $3.33 \pm 0.51^{a}$ \\
\hline $\begin{array}{l}\text { Asitlik } \\
\text { Acidity }\end{array}$ & $4.00 \pm 1.26^{a}$ & $4.33 \pm 0.51^{a}$ & $4.00 \pm 0.63^{\mathrm{a}}$ \\
\hline $\begin{array}{l}\text { Koku } \\
\text { Odor }\end{array}$ & $3.83 \pm 1.32^{\mathrm{a}}$ & $4.50 \pm 0.54^{\mathrm{a}}$ & $4.50 \pm 0.83^{\mathrm{a}}$ \\
\hline $\begin{array}{l}\text { Genel beğeni } \\
\text { Overall acceptability }\end{array}$ & $3.58 \pm 0.83^{a}$ & $4.21 \pm 0.85^{a}$ & $4.16 \pm 0.81^{\mathrm{a}}$ \\
\hline $\begin{array}{l}\text { *Veriler } 2 \text { tekrarlı } \\
\text { değerlerini ifade et } \\
\text { Tukey testi sonuç } \\
\text { farklılığı }(p<0.05) \text { ifa }\end{array}$ & $\begin{array}{l}\text { erilerin orta } \\
\text { ektedir. Ayr } \\
\text { Ina göre g } \\
\text { etmektedir. }\end{array}$ & $\begin{array}{l}\text { lama } \pm \text { sta } \\
\text { וn satırdaki } \\
\text { ruplar aras }\end{array}$ & $\begin{array}{l}\text { dart sapma } \\
\text { arklı harfler } \\
\text { ida anlamlı }\end{array}$ \\
\hline
\end{tabular}

Formülasyonda kullanılacak olan MRE oranı (\%1.5, v/v) belirlendikten sonra ikinci duyusal 
değerlendirme bileşimdeki sitrik asit miktarının değiştirilmesiyle gerçekleştirilmiştir. Buna göre $\% 0.10, \% 0.15$ ve $\% 0.20(\mathrm{w} / \mathrm{v})$ sitrik asit içeren soğuk çaylar duyusal olarak değerlendirilmiştir. Tüm duyusal parametreler açısından örnekler değerlendirildiğinde sitrik asit miktarının değiştirilmesi örnekler arasında anlamlı bir fark $(P>0.05)$ oluşturmamıştır. Bununla birlikte tüm duyusal parametreler göz önüne alındığında daha çok beğeni puanı alan \%0.15 (w/v) sitrik asit içeren C2 kodlu soğuk çay örneği seçilmiştir.

Çizelge 4. Sitrik asit miktarının belirlenmesi

Table 4. Determination the amount of citric acid

\begin{tabular}{|c|c|c|c|}
\hline \multirow[b]{2}{*}{$\begin{array}{l}\text { Duyusal özellikler } \\
\text { Sensory properties }\end{array}$} & \multicolumn{3}{|c|}{$\begin{array}{l}\text { Sitrik asit }(\%, w / v) \\
\text { Citric acid }(\%, w / v)\end{array}$} \\
\hline & 0.10 & 0.15 & 0.20 \\
\hline $\begin{array}{l}\text { Renk } \\
\text { Color }\end{array}$ & $4.33 \pm 1.00^{a}$ & $4.55 \pm 0.72^{a}$ & $4.66 \pm 0.70^{a}$ \\
\hline $\begin{array}{l}\text { Tatlılık } \\
\text { Sweetness }\end{array}$ & $3.55 \pm 0.88^{a}$ & $4.11 \pm 0.78^{a}$ & $3.66 \pm 1.00^{\mathrm{a}}$ \\
\hline $\begin{array}{l}\text { Asitlik } \\
\text { Acidity }\end{array}$ & $3.66 \pm 1.11^{\mathrm{a}}$ & $4.33 \pm 0.86^{\mathrm{a}}$ & $3.88 \pm 1.16^{\mathrm{a}}$ \\
\hline $\begin{array}{l}\text { Koku } \\
\text { Odor }\end{array}$ & $4.00 \pm 1.00^{a}$ & $3.77 \pm 1.09^{a}$ & $4.22 \pm 1.09^{a}$ \\
\hline $\begin{array}{l}\text { Genel beğeni } \\
\text { Overall acceptability }\end{array}$ & $3.66 \pm 0.86^{a}$ & $4.22 \pm 0.97^{a}$ & $3.77 \pm 1.20^{a}$ \\
\hline $\begin{array}{l}\text { *Veriler } 2 \text { tekrarlı } \\
\text { değerlerini ifade e } \\
\text { Tukey testi sonuç } \\
\text { farklılığı }(P<0.05) \text { ifa }\end{array}$ & $\begin{array}{l}\text { rilerin ort } \\
\text { ektedir. Ay } \\
\text { na göre } \\
\text { etmektedir }\end{array}$ & $\begin{array}{l}\text { ma } \pm \text { sta } \\
\text { satırdaki } \\
\text { plar aras }\end{array}$ & $\begin{array}{l}\text { lart sapma } \\
\text { rklı harfler } \\
\text { da anlamlı }\end{array}$ \\
\hline
\end{tabular}

Çizelge 5. Sakaroz miktarının belirlenmesi

Table 5. Determination the amount of sucrose

\begin{tabular}{|c|c|c|c|}
\hline \multirow[b]{2}{*}{$\begin{array}{l}\text { Duyusal özellikler } \\
\text { Sensory properties }\end{array}$} & \multicolumn{3}{|c|}{$\begin{array}{l}\text { Sakaroz }(\%, w / v) \\
\text { Sucrose }(\%, w / v)\end{array}$} \\
\hline & 6 & 7 & 8 \\
\hline $\begin{array}{l}\text { Tatlılık } \\
\text { Sweetness }\end{array}$ & $3.33 \pm 0.50^{\mathrm{a}}$ & $4.00 \pm 1.00^{b}$ & $4.44 \pm 0.72^{b}$ \\
\hline $\begin{array}{l}\text { Asitlik } \\
\text { Acidity }\end{array}$ & $3.66 \pm 1.32^{\mathrm{a}}$ & $3.77 \pm 0.83^{\mathrm{a}}$ & $3.66 \pm 0.70^{\mathrm{a}}$ \\
\hline $\begin{array}{l}\text { Koku } \\
\text { Odor }\end{array}$ & $3.88 \pm 0.92^{a}$ & $4.11 \pm 0.78^{a}$ & $4.55 \pm 0.72^{a}$ \\
\hline $\begin{array}{l}\text { Genel beğeni } \\
\text { Overall acceptability }\end{array}$ & $3.33 \pm 0.70^{\mathrm{a}}$ & $3.88 \pm 1.26^{b}$ & $4.55 . \pm 0.72^{b}$ \\
\hline $\begin{array}{l}\text { *Veriler } 2 \text { tekrarl } \\
\text { değerlerini ifade } \\
\text { Tukey testi sonu } \\
\text { farklılığı }(P<0.05) \text { if }\end{array}$ & $\begin{array}{l}\text { verilerin ort } \\
\text { mektedir. Ay } \\
\text { arına göre } \\
\text { e etmektedir }\end{array}$ & $\begin{array}{l}\text { lama } \pm \text { sta } \\
\text { I satırdaki } \\
\text { ruplar aras }\end{array}$ & $\begin{array}{l}\text { dart sapma } \\
\text { arklı harfler } \\
\text { da anlamlı }\end{array}$ \\
\hline
\end{tabular}

MRE ve sitrik asit miktarının belirlenmesinin ardından son olarak sakaroz miktarı belirlenmiştir. Asitlik ve koku açısından örnekler arasında anlamlı bir fark ( $P>0.05$ ) olmamakla birlikte genel beğeni, koku ve tatlılık açısından en yüksek puanı $\% 8$ (w/v) sakaroz içeren T3 kodlu örnek almıştır. Sonuç olarak kalorisi azaltılmış soğuk çay formülasyonu T3 kodlu örnekteki oranlar dikkate alınarak hazırlanmış ve panelistlerin değerlendirmesine sunulmuştur.

Kalorisi azaltılmış soğuk çayların duyusal özellikleri

Sakaroz ile üretilen soğuk çayın kalorisini azaltmak amacıyla ksilitol ve sorbitol kullanılmıştır. Şeker alkolü içeren soğuk çaylar tüm duyusal parametreler yönünden sakaroz içerene göre daha yüksek beğeni puanı aldığı tespit edilmiştir (Çizelge 6). Tatıılık, aroma, asitlik, ağız hissi ve genel beğeni açısından ksilitol içeren örnek ile sorbitol içeren örnek arasında anlamlı bir fark $(P>0.05)$ bulunmamıştır ve sakaroz içeren soğuk çaya kıyasla daha çok tercih edilmişlerdir. Renk ve asitlik açısından soğuk çayların kimyasal metotlar ile tespit edilen özellikleri ile panelistler tarafından belirlenen özelliklerinin birbirinden farklı olduğu görülmüştür. Şeker alkollü soğuk çaylar asitlik açısından, sorbitollü örnek ise renk açısından daha çok beğeni puanı aldığı tespit edilmiştir. Tatlılık olarak sakaroz ile aynı miktarda şeker alkolü kullanılmasına rağmen kalorisi azaltılmış soğuk çaylar daha tatlı algılanmıştır. Bu sonuç şeker alkollerinin sakaroz ikamesi olarak daha iyi ve daha düşük kalorili bir alternatif olabileceğini açığa çıkarmaktadır. Şeker alkolü içeren her iki soğuk çay 5 puanlı hedonik testte tüm duyusal parametrelerin ortalaması olarak 3.73 puan aldığı ve ortalama 2.95 puan alan sakarozlu soğuk çaydan daha çok beğenildiği ortaya konulmuştur. Aonla-zencefil düşük kalorili içeceklerinin duyusal özelliklerinin belirlendiği bir çalışmada aspartam ilavesiyle hazırlanan içeceğin sakaroz içeren örneğe göre duyusal panel üyeleri tarafından daha çok beğenildiği belirlenmiştir (Gaikwad, 2012). İçeceklerin duyusal özellikleri uçucu ve uçucu olmayan fenolik bileşikler, organik asit ve şeker gibi bileşiklerin varlığı ile de ilgilidir (Yu ve ark., 2014). Mor reyhanın uçucu ve uçucu olmayan fenolik bileşiklerce zengin olduğu düşünüldüğünde şeker alkolleri ile soğuk çay 
formülasyonunda iyi bir uyum sağladığı söylenebilir (Flanigan ve Niemeyer, 2014). Bununla birlikte çalışmada geliştirilen soğuk çaylar şeker ve yapay tatlandırıcıların dezavantajları düşünüldüğünde oldukça iyi bir seçenek olabilecek niteliktedir.

Çizelge 6. Soğuk çayların duyusal özellikleri Table 6. Sensory properties of iced teas

\begin{tabular}{lccc}
\hline & \multicolumn{3}{c}{$\begin{array}{c}\text { Soğuk çay örnekleri } \\
\text { Iced tea samples }\end{array}$} \\
\cline { 2 - 4 } $\begin{array}{l}\text { Duyusal özellikler } \\
\text { Sensory properties }\end{array}$ & $\mathrm{T} 3$ & $\mathrm{~T} 4$ \\
\hline $\begin{array}{l}\text { Renk } \\
\text { Color }\end{array}$ & $3.53 \pm 1.1^{\mathrm{b}}$ & $3.75 \pm 0.89^{\mathrm{b}}$ & $4.03 \pm 0.91^{\mathrm{a}}$ \\
\hline Koku & & & \\
Odor & $3.16+0.94^{\mathrm{a}}$ & $3.66+1.02^{\mathrm{a}}$ & $3.63+0.88^{\mathrm{a}}$ \\
\hline Tatlılık & & & \\
Sweetness & $2.75 \pm 0.96^{\mathrm{b}}$ & $3.85 \pm 0.73^{\mathrm{a}}$ & $3.77 \pm 0.94^{\mathrm{a}}$ \\
\hline $\begin{array}{l}\text { Aroma } \\
\text { Aroma }\end{array}$ & $2.80 \pm 0.99^{\mathrm{b}} 3.73 \pm 0.73^{\mathrm{a}}$ & $3.76 \pm 0.85^{\mathrm{a}}$ \\
\hline $\begin{array}{l}\text { Asitlik } \\
\text { Acidity }\end{array}$ & $2.92 \pm 1.08^{\mathrm{b}} 3.47 \pm 0.93^{\mathrm{a}}$ & $3.37 \pm 1.05^{\mathrm{ab}}$ \\
\hline $\begin{array}{l}\text { Ağı hissi } \\
\text { Mouth feeling }\end{array}$ & $2.5 \pm 0.93^{\mathrm{b}} 3.73 \pm 0.90^{\mathrm{a}}$ & $3.86 \pm 0.89^{\mathrm{a}}$ \\
\hline $\begin{array}{l}\text { Genel beğeni } \\
\text { Overall acceptability }\end{array}$ & $2.97 \pm 0.94^{\mathrm{b}} 3.90 \pm 0.87^{\mathrm{a}}$ & $3.82 \pm 0.81^{\mathrm{a}}$ \\
\hline
\end{tabular}

*Veriler 2 tekrarlı verilerin ortalama \pm standart sapma değerlerini ifade etmektedir. Aynı satırdaki farklı harfler Tukey testi sonuçlarına göre gruplar arasında anlamlı farklılığı $(P<0.05)$ ifade etmektedir.

${ }^{1}$ T3: sakaroz ile hazırlanan soğuk çay örneği, T4: ksilitol ile hazırlanan soğuk çay örneği, T5: sorbitol ile hazırlanan soğuk çay örneği.

\section{Sonuçlar}

Günümüzde sağlıklı nesillerin yetişmesi bakımından artan obezite ve diyabet gibi kronik rahatsızlıklarla mücadele önem kazanmaktadır. Bu rahatsızlıklardan dolayı şeker içeriği azaltılmış veya şekersiz ürünlere olan talep giderek artmaktadır. Bu kapsamda yavaş metabolize edilen kalorisi az tatlandırıcı olan şeker alkollerinin çeşitli ürünlerde kullanılabilirliği çeşitli çalışmalarla desteklenmektedir. Şekersiz ya da şekeri azaltılmış diyet ürünler arasında özellikle de fonksiyonel özelliğe sahip olanları daha fazla talep görmekte ve böylece, daha sağlıklı, doğal ve kalorisi azaltılmış ürünler ön plana çıkmaktadır. Bu çalışmada mor reyhan ekstraktı ve kalorisi sakaroza göre daha az olan şeker alkolleri kullanılarak soğuk çaylar hazırlanmıştır. Düşük kalorili mor reyhan soğuk çaylarınn duyusal özellikleri, sakaroz içeren örnekle karşılaştırıldığında anlamlı şekilde daha tatlı algılanmış ve daha yüksek beğeni puanları almıştır. Duyusal ve fizikokimyasal analizler sonrası elde edilen sonuçlar göz önüne alındığında sakaroz ikamesi olarak şeker alkollerinin ve mor reyhan kullanımının soğuk çayların özelliklerini geliştirdiği tespit edilmiştir.

\section{Çıkar Çatışması Beyanı: Makale yazarları} aralarında herhangi bir çıkar çatışması olmadığını beyan ederler.

Yazar Katkısı: MÇ çalışmayı planlamış, EK, ED ve TŞ deneysel çalışmayı yürütmüş, SB verileri analiz etmiş ve makaleyi yazmış, MÇ makalenin son kontrollerini yapmıştır.

\section{Kaynaklar}

Alaşalvar, H., \& Çam, M. (2020). Ready to drink iced teas from microencapsulated spearmint (Mentha spicata $L$ .) and peppermint ( Mentha piperita L .) extracts: physicochemical , bioactive and sensory characterization. Journal of Food Measurement and Characterization, 14(3), 1366-1375. https://doi.org/10.1007/s11694-020-00386-4

Bello, F., Vázquez, D. E., Almirón, N., Cocco, M., \& Meier, G. E. (2015). Sensorial Analysis as an Instrument for Color Measurement in "Satsuma" and "Nova" Mandarın Fruit. Acta Horticulturae, 1065(1065), 1491-1496.

https://doi.org/10.17660/ActaHortic.2015.1065.189

Butt, M. S., Pasha, I., Tufail, F., \& Anjum, F. M. (2002). Use of low absorptive sweeteners in cakes. International $J$ Agriculture and Biology, 4(2), 249-251.

Cammenga, H. K., Figura, L. O., \& Zielasko, B. (1996). Thermal behaviour of some sugar alcohols. Journal of Thermal Analysis, 47(2), 427-434. https://doi.org/10.1007/BF01983984

Cemeroğlu, B. S., Gıda Analizleri, Ankara Üniversitesi Mühendislik Fakültesi, Ankara, 2013.

Cheng, N., Barbano, D. M., \& Drake, M. A. (2018). Hunter versus $\mathrm{CIE}$ color measurement systems for analysis of milk-based beverages. Journal of Dairy Science, 101(6), 4891-4905. https://doi.org/10.3168/jds.201714197

de Beer, D., Pauck, C. E., Aucamp, M., Liebenberg, W., Stieger, N., van der Rijst, M., \& Joubert, E. (2018). Phenolic and physicochemical stability of a functional beverage powder mixture during storage: effect of the microencapsulant inulin and food ingredients. Journal of the Science of Food and Agriculture, 98(8), 2925-2934. https://doi.org/10.1002/jsfa.8787 
DellaValle, D. M., Malek, A. M., Hunt, K. J., Peter, J. Vs., Greenberg, D., \& Marriott, B. P. (2018). Low-calorie sweeteners in foods, beverages, and food and beverage additions: NHANES 2007-2012. Current Developments in Nutrition, 2(12), 1-5. https://doi.org/10.1093/cdn/nzy024

Diffy, V.B., \& G.H. Anderson, (1998). Use of nutritive and non-nutritive sweeteners. Journal of the American Dietetic Association, 98, 580-7.

Flanigan, P. M., \& Niemeyer, E. D. (2014). Effect of cultivar on phenolic levels, anthocyanin composition, and antioxidant properties in purple basil (Ocimum basilicum L.). Food Chemistry, 164, 518-526. https://doi.org/10.1016/j.foodchem.2014.05.061

Gaikwad, K. (2012). Studies on the Development and Shelf Life of Low Calorie Herbal Aonla- Ginger RTS Beverage by Using Artificial Sweeteners. Journal of Food Processing and Technology, 4(1), 1-4. https://doi.org/10.4172/2157-7110.1000200

Godswill, A. C. (2017). Sugar Alcohols: Chemistry , Production, Health Concerns and Nutritional Importance of Mannitol, Sorbitol, Xylitol, and Erythritol. International Journal of Advanced Academic Research, 3(2), 31-66.

Grembecka, M. (2015). Sugar alcohols-their role in the modern world of sweeteners: a review. European Food Research and Technology, 241(1), 1-14. https://doi.org/10.1007/s00217-015-2437-7

Gürkan, H., Boran, O. S., \& Hayaloğlu, A. A. (2019). Influence of purple basil extract (Ocimum basilicum L.) on chemical composition, rheology and antioxidant activity of set-type yoghurt. Mljekarstvo, 69(1), 42-52. https://doi.org/10.15567

Kim, S., Kim, M., Song, Y. B., Cho, M. K., \& Song, Y. O. (2016). Development of low calorie roasted radish tea beverage with anti-oxidant activity. Food Science and Biotechnology, 25, 113-118. https://doi.org/10.1007/s10068-016-0107-6

Koroch, A. R., Simon, J. E., \& Juliani, H. R. (2017). Essential oil composition of purple basils, their reverted green varieties (Ocimum basilicum) and their associated biological activity. Industrial Crops and Products, 107(2017), 526-530. https://doi.org/10.1016/j.indcrop.2017.04.066

Kroger, M., Meister, K., \& Kava, R. (2006). Low-calorie sweeteners and other sugar substitutes: A review of the safety issues. Comprehensive Reviews in Food Science and Food Safety, 5(2), 35-47. https://doi.org/10.1111/j.1541-4337.2006.tb00081.x

Özünlü, O., \& Ergezer, H. (2019). İnfüzyon Yöntemi Kullanılarak Kurutulmuş Enginar Çanak Yaprağı Katkılı Soğuk Yeşil Çay Üretimi. Akademik Gıda, 17(4), 458467. https://doi.org/10.24323/akademik-gida.667257

Pedro, A. C., Moreira, F., Granato, D., \& Rosso, N. D. (2016). Extraction of bioactive compounds and free radical scavenging activity of purple basil (Ocimum basilicum L.) leaf extracts as affected by temperature and time. Anais da Academia Brasileira de Ciencias, 88(2),
1055-1068. https://doi.org/10.1590/00013765201620150197

Phippen, W. B., \& Simon, J. E. (1998). Anthocyanins in Basil (Ocimum basilicum L.). Journal of Agricultural and Food Chemistry, 46(5), 1734-1738. https://doi.org/10.1021/jf970887r

Prinsi, B., Morgutti, S., Negrini, N., Faoro, F., \& Espen, L. (2020). Insight into composition of bioactive phenolic compounds in leaves and flowers of green and purple basil. Plants, 9(1). https://doi.org/10.3390/plants9010022

Samaniego-Vaesken, M. de L., Partearroyo, T., Cano, A., Urrialde, R., \& Varela-Moreiras, G. (2019). Novel database of declared low- and no-calorie sweeteners from foods and beverages available in Spain. Journal of Food Composition and Analysis, 82, 103234. https://doi.org/10.1016/j.jfca.2019.103234

Sylvetsky, A. C., \& Rother, K. I. (2016). Trends in the consumption of low-calorie sweeteners. Physiology and Behavior, 164, 446-450. https://doi.org/10.1016/j.physbeh.2016.03.030

Szymanowska, U., Złotek, U., Karä̈, M., \& Baraniak, B. (2015). Anti-inflammatory and antioxidative activity of anthocyanins from purple basil leaves induced by selected abiotic elicitors. Food Chemistry, 172, 71-77. https://doi.org/10.1016/j.foodchem.2014.09.043

Toğrul, Ö. \& Hayoğlu, ì. (2020). Yeni bir izotonik içecek olarak; nar, kızılcık ve karadut suları ile zenginleştirilmiş elma suyu üretim olanakları. Harran Tarım ve Gıda Bilimleri Dergisi, 24(2): 165-173. DOI: 10.29050/harranziraat.622179

Wu, Y., Wang, Y., Zhang, W., Han, J., Liu, Y., Hu, Y., \& Ni, L. (2014). Extraction and preliminary purification of anthocyanins from grape juice in aqueous two-phase system. Separation and Purification Technology, 124, 170-178.

https://doi.org/10.1016/j.seppur.2014.01.025

Yu, P., Yeo, A. S. L., Low, M. Y., \& Zhou, W. (2014). Identifying key non-volatile compounds in ready-todrink green tea and their impact on taste profile. Food Chemistry, 155, 9-16. https://doi.org/10.1016/j.foodchem.2014.01.046

Złotek, U., Szychowski, K. A., \& Świeca, M. (2017). Potential in vitro antioxidant, anti-inflammatory, antidiabetic, and anticancer effect of arachidonic acid-elicited basil leaves. Journal of Functional Foods, 36, 290-299. https://doi.org/10.1016/j.jff.2017.07.024

Złotek, U., Szymanowska, U., Karaś, M., \& Świeca, M. (2016). Antioxidative and anti-inflammatory potential of phenolics from purple basil (Ocimum basilicum L.) leaves induced by jasmonic, arachidonic and $\beta$ aminobutyric acid elicitation. International Journal of Food Science and Technology, 51(1), 163-170. https://doi.org/10.1111/ijfs.12970

Warshaw, H. S., \& Powers, M. A. (1999). A search for answers about foods with polyols. The Diabetes Educator, 25, 307-21. 